\title{
Epidemiological, clinical and therapeutic aspects of post- traumatic lesions of the posterior segment
}

\author{
AS Sow ${ }^{1}$, H Kane ${ }^{1 *}$, PA Ndoye Roth ${ }^{1}$, JM Ndiaye ${ }^{1}$, AM Ka ${ }^{2}$, JP Diagne ${ }^{2}$, HM Diallo ${ }^{2}$, M Nguer $^{1}$, S \\ Sow $^{2}$, EA Bâ ${ }^{1}$ \\ ${ }^{1}$ Department of Ophthalmology, Aristide Le Dantec Hospital, Dakar, Senegal \\ ${ }^{2}$ Department of Ophthalmology, Abass Ndao Hospital, Dakar, Senegal
}

Received: 01 August, 2016; Accepted: 31 August, 2016; Published: 09, September, 2016

*Corresponding author: Habsa Kane, Department of Ophthalmology, Aristide Le Dantec Hospital, Dakar, Senegal; E-mail: hapikane@gmail.com

\begin{abstract}
Purpose: To determine the epidemiological, clinical and therapeutic aspects of post-traumatic lesions of the posterior segment.

Patients and methods: A retrospective study was conducted during the period from 1 January 2011 to 31 December 2013.We identified the records of patients with post-traumatic lesions (nonsurgical) of the posterior segment.

Results: Injuries accounted for $7.05 \%$ of consultations including 9.3\% interesting the posterior segment. The mean age was 23.14 years. The age group of 16- 45 years was the most affected with $56.14 \%$ of cases.

The sex ratio was 6.13 . More than $25 \%$ of patients had consulted more than a year after the trauma. The decrease in visual acuity was the most frequent reason for consultation with $96.49 \%$ of cases. Circumstances of trauma were dominated by brawls. Metal objects and stone jets were the most common causal agents. Closed globe injuries represented 44 cases $(77.19 \%)$. In these cases the lesions of the posterior segment were dominated by retinal detachment $(36.37 \%)$ followed by fibrous vitreous organizations $(29.55 \%)$. In open globe injuries, the lesions of the posterior segment were dominated by retinal detachment (61.54\%), followed by vitreous hemorrhage $(30.77 \%)$ We noted as complications and sequelae two cases of endophthalmitis, 13 adhesions iridocristalliniennes and 2 cases of ocular phtyse. Ten patients (17.54\%) were hospitalized. Nineteen patients had medical and surgical treatment. Among them, eight patients had ocular suture, and nine patients, cataract surgery. Two patients had a vitrectomy, and one patient had a scleral buckling. The final visual acuity could be assessed only in 24 cases $(42.10 \%)$ It was superior or equal to $5 / 10^{\text {th }}$ in one case $(4.2 \%)$, and less than $1 / 10^{\text {th }}$ in 23 cases $(95.8 \%)$.
\end{abstract}

Conclusion: Post-traumatic lesions of the posterior segment are varied and can cause significant anatomical and functional impact. Their care remains difficult. Increased awareness of the population would reduce the incidence and improve the coverage.

Keywords: Post-traumatic lesions; Posterior segment

\section{Introduction}

Eye injuries are a major public health problem. For one of their sometimes serious complications, but also by their care remains difficult despite advances in surgery.
The retrospective study conducted at the Hospital Aristide Le Dantec was to determine the epidemiological, clinical and therapeutic post-traumatic lesions of the posterior segment of the globe.

\section{Patients and Methods}

During the period from 1 January 2011 to 31 December 2013, we identified the records of patients with post-traumatic lesions (non-surgical) of the posterior segment.

On the following data sheet investigations were identified, marital status, consultation deadline, histories, clinical signs, results of Ultrasonography of the posterior segment, the received treatment and post-treatment changes.

\section{Results}

\section{Frequency}

During the study period, injuries accounted for $7.05 \%$ of consultations including 9.3\% interesting the posterior segment.

\section{Demographic data}

The mean age was 23.14 years with extremes of 4 and 75 years. The subjects from 0 to 15 years old represented 20 cases, including 16 male ( $80 \%$ of cases). The age group of $16-45$ years was the most affected with 32 cases ( $56.14 \%$ of cases).

The sex ratio was 6.13. The distribution of patients according to age group and gender is presented in (Table 1).

\begin{tabular}{|l|l|l|l|}
\hline \multirow{2}{*}{ Table 1: Distribution according to the sex and the age bracket. } \\
\hline & \multicolumn{3}{|c|}{ Sex } \\
\cline { 2 - 4 } Age & Female & Male & Total \\
\hline $\mathbf{0}$ - $\mathbf{1 5}$ years & 4 & 16 & $20(35,09 \%)$ \\
\hline $\mathbf{1 6}-\mathbf{4 5}$ years & 3 & 29 & $32(56,14 \%)$ \\
\hline $\mathbf{4 6}-\mathbf{7 5}$ years & 1 & 4 & $5(8,77 \%)$ \\
\hline
\end{tabular}




\section{Clinical data}

\section{Histories}

Three patients $(5.26 \%$ of the cases) reported histories or a particular field, two cases of phacoexérèse, and a case of glaucoma.

\section{Consultation deadline}

It ranged between 1 and 12 years.

More than $25 \%$ of patients had consulted more than a year after the trauma. The various consultation deadlines are reported in (Figure 1).

\section{The reasons for consultation}

The decrease in visual acuity was the most frequent reason for consultation with 55 cases ( $96.49 \%$ of cases). It was associated with redness and pain in 37 cases $(64.91 \%$ of cases).

Other reasons for consultation were in order of frequency, watery eyes (19.3\%) photophobia $(17.54 \%)$, and bleeding $(5.26 \%)$.

\section{Circumstances of trauma}

These circumstances were identified in 49 patients $(5.46 \%$ of cases). They were dominated by brawls in men. Domestic accidents were the first circumstance of occurrence in women, while playful accidents were the first circumstance in children. Different circumstances are shown in (Figure 2).

\section{Nature of the traumatic object}

The causal agent was not specified in almost $18 \%$ of cases. In other cases, metal objects and stone jets were the most common causal agents. The various traumatic agents are summarized in (Figure 3).

\section{Laterality}

The disease was unilateral in $100 \%$ of cases. The right eye was achieved in 30 cases (52.63\% of cases).

\section{The initial visual acuity}

Visual Acuity (VA) was not specified in 5 cases. For others, it was less than $1 / 10^{\text {th }}$ in 48 patients $(92,3 \%$ of cases),it was between $1 / 10^{\text {th }}$ and $5 / 10^{\text {th }}$ in 2 patients $(3,85 \%$ of cases $)$ and greater than $5 / 10^{\text {th }}$ in 2 patients $(3,85 \%$ of cases $)$.

\section{Type of trauma}

Closed globe injuries represented 44 cases (77.19\%). In these cases it was noted besides the lesions of the posterior segment, an adnexal reached in 40 cases (90.9\%) and the anterior segment in 35 cases $(79.55 \%)$.The lesions of the posterior segment were dominated by retinal detachment $(36.37 \%)$ followed by fibrous vitreous organizations (29.55\%).

Open globe injuries regrouped ten penetrating wounds, two intraocular foreign bodies and rupture of the globe. Adnexal and anterior segment injuries were reported in $100 \%$ of cases. The lesions of the posterior segment were dominated by retinal detachment (61.54\%), followed by vitreous hemorrhage
(30.77\%). The various lesions of the posterior segment are reported in (Table 2).

\section{Complications and sequelae}

We noted two cases of endophthalmitis, 13 adhesions iridocristalliniennes and 2 cases of ocular phtyse.

\section{Therapeutic}

\section{Treatment}

Ten patients (17.54\%) were hospitalized. Forty-nine patients had medical treatment. Nineteen patients had medical

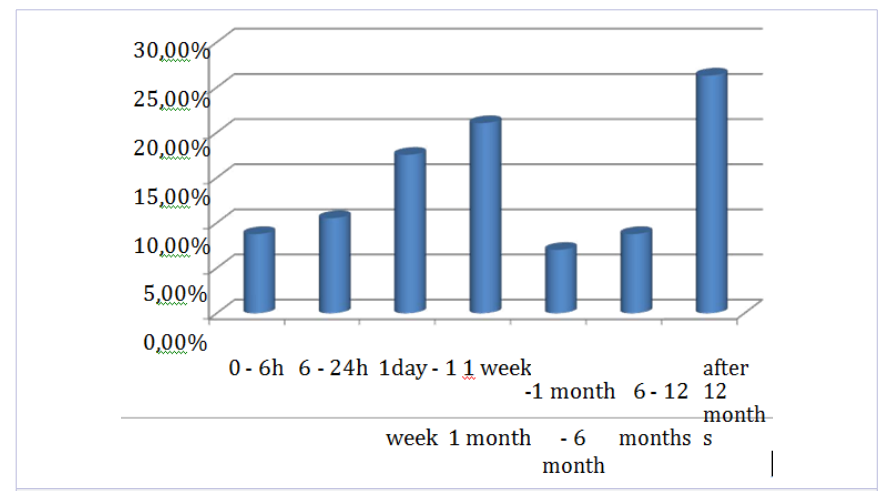

Figure 1: Consultation deadline.

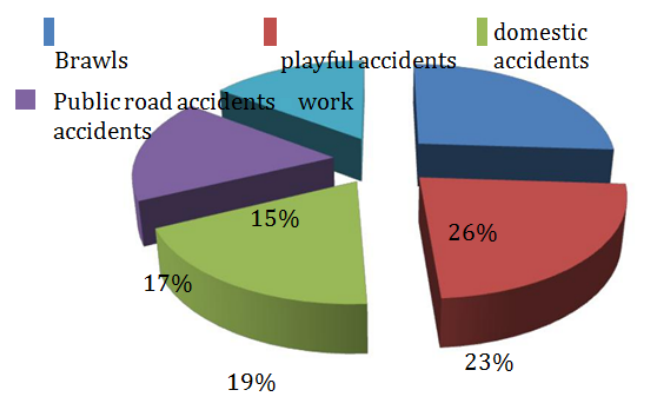

Figure 2: Circumstances of trauma.

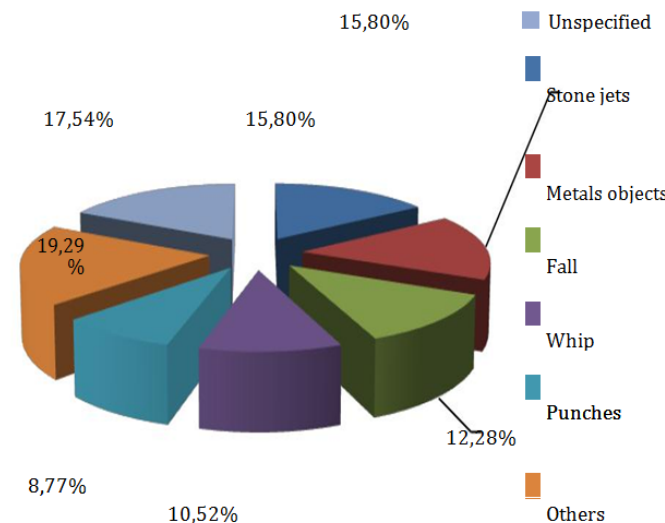

Figure 3: Traumatic agents. 
Table 2: Lesions of the posterior segment by type of trauma.

\begin{tabular}{|l|l|l|}
\hline & \multicolumn{2}{l|}{ Closed globe injury Open globe injury } \\
\hline Retinal Detachment & 16 & 8 \\
\hline $\begin{array}{l}\text { Fibrous vitreous } \\
\text { organizations }\end{array}$ & 13 & 3 \\
\hline Vitreous hemorrhage & 10 & 5 \\
\hline Optical atrophy & 3 & 0 \\
\hline Retinal edema & 3 & 0 \\
\hline Macular hole & 2 & 0 \\
\hline Retinal Hemorrhage & 2 & 0 \\
\hline $\begin{array}{l}\text { Posterior vitreous } \\
\text { Detachment }\end{array}$ & 1 & 1 \\
\hline Choroidal rupture & 1 & 0 \\
\hline
\end{tabular}

and surgical treatment. Among them, eight patients had ocular suture, and nine patients, cataract surgery. Two patients had a vitrectomy, and one patient had a scleral buckling.

\section{Post treatment visual acuity}

The final visual acuity could be assessed only in 24 cases $(42.10 \%)$. It was superior or equal to $5 / 10^{\text {th }}$ in one case $(4.2 \%)$, and less than $1 / 10^{\text {th }}$ in 23 cases (95.8\%).

\section{Discussion}

\section{Frequency}

The frequency of injuries was $7.05 \%$, which approximates to Oyoua results in Côte d'Ivoire [1] which reported a rate of $7.7 \%$. Kante [2] found a rate was much lower (1.22\%). The lesions of the posterior segment represented $9.3 \%$ of all injuries. Our figures are higher than those described in the literature $[3,4]$.

\section{Demographic data}

Male dominance was marked with a sex ratio of 6.13 . This dominance was even more pronounced for the age group of 0-15 years with $80 \%$ of male patients. Other series found this male dominance $[5,6,7]$. This could be explained by the fact that men were more often involved in traumatic to risk activities.

The mean age was 23.14 years. Khalki [5] reported a mean age of 24.36 years, while Seck [8] found a higher age 34.6 years. The most affected age group was that of 16-45 years, which approximates the results of Kaya [9] which noted a peak between 16 and 35 years. The age group of 0-15 years accounted for $35.09 \%$ of the cases in our series, which joins other data sets [5, 8].

\section{Clinical data}

\section{Consultation deadline}

Only $8.77 \%$ of patients had consulted in $6 \mathrm{~h}$ after injury. Lam [6] found a rate close to $10 \%$. About $20 \%$ of our patients had consulted before the 24th hour. This figure remains low compared to other African series $[6,10]$ which reported a rate above $50 \%$. Patients who had consulted more than a year after the trauma accounted for over $25 \%$ of cases, and 24 patients (42.1\% of cases) had retinal detachment. Trigui [11] noted that the retinal detachment occurred in over $50 \%$ of cases, a year after the trauma. Verin [12] reported that in developing countries, the consultation deadline for ocular trauma was often delayed due to the ignorance of populations to their severity and the necessity of an urgent coverage.

\section{Circumstances of occurrence}

Brawls were the first circumstance of occurrence the traumas of the posterior segment. They also occupied the first place in other series [5, 11].Playful accidents were the second circumstance all ages but figured first in children. Which joined other data $[6,13]$, which recorded the playful accidents were the main circumstances of trauma in children. Domestic accidents were the third circumstance as well as for Lam [6]. In other series they represented the first one [14] or the second circumstance [5]. Public road accidents were placed fourth. They represented the first circumstance for Tchabi in Benin [15], while for others $[5,6]$, they were only the fifth occasion. Workplace accidents were the fifth occasion with a frequency of $15 \%$. They ranked fourth but with a lower frequency for Lam [6] and Khalki [5]. Ngondi [16] reported that the worker is not sufficiently accountable for the risks of accidents. He noted the importance of preventive eye exams and development of business advocacy strategies.

Stone jets and metal objects were the main traumatic agents with a rate close to $16 \%$. Metal objects were the first one cause almost $20 \%$ of cases for Gbe [7]. Khalki [5] found the stone jets as first one cause with a rate close to 19\%. Lam [6] found the punches as the first one cause with a frequency of $16 \%$, which is almost double our results, where punches occupied only the fourth rank.

Thus the nature of the traumatic agents and frequency vary depending on the environment and socio-cultural habits.

\section{Laterality}

The disease was unilateral in $100 \%$ of cases, joining Gaboune results [17]. Other series [6, 8] reported bilateral involvement, but with a lesser frequency.

\section{Type of trauma}

Closed globe injuries accounted for over $75 \%$ of our series, joining the other data $[6,18]$ who reported that predominance.

The retinal detachment was the most common injury with 24 cases (42.1\% of cases), joining Frau [19] who found a rate of $43 \%$. This rate remains very variable depending on the series [5, 20]. In the open globe injury, retinal detachment were found in 8 cases (47.06\% of cases), joining the Rouberol data [21].

The vitreous hemorrhage was found in 15 cases $(26.32 \%$ of cases), which joined the Aberkane data. [20].

An optical atrophy was found at 3 patients (5.26\%) who were victims of violent trauma (brawl, fall). Levin [22] reported that the violent trauma at the young men was the most common cause of traumatic optical neuropathy. 
In 3 cases (5.26\%) we found a retinal edema. Frau [19] noted a rate near twice higher.

Two patients had macular hole (3.51\%). These data joining those of Aaberg [23]. We objectified 2 posterior vitreous detachments (3.51\%). This rate was significantly lower than the Savi data [18], who reported rates of at least 5 times higher.

Choroidal rupture was found in 1 case $(1.75 \%)$. These data are significantly lower than those of Khalki [5].

\section{Therapeutic}

Forty-nine patients had medical treatment. Nineteen patients had medical and surgical treatment. Among them, eight patients had ocular suture, and nine patients, cataract surgery. Two patients with vitreous organization had a vitrectomy, and a patient with retinal detachment had scleral buckling.

Both patients presenting a macular hole had no surgical treatment. One of them had consulted less than a month after the injury, the monitoring was recommended owed made by the possibility of spontaneous closure [24]. For the other patient, the deadline consultation exceeding one year. This seniority was a factor of bad prognosis poor prognosis, with a surgical success rate lower than $50 \%$ [25].

The post treatment visual acuity could be assessed in 24 patients (42.10\%). It was less than $1 / 10^{\text {th }}$ in almost $96 \%$ of cases. This figure is very high compared to the data of the literature $[5,6,11]$ where the rate does not exceed $60 \%$. Our results can be explained by the already weak pre therapeutic visual acuity with over $90 \%$ of patients with lower acuity at $1 / 10^{\text {th }}$. Another explanation is that the lesions of the posterior segment were worse prognosis as confirmed by Kuhn [14]. But also bias the study related to incomplete records with a final visual acuity evaluated in less than $50 \%$ of patients.

\section{Conclusion}

Post-traumatic lesions of the posterior segment are varied and can cause significant anatomical and functional impact. Increased awareness of the population would reduce the incidence and improve the coverage.

The author(s) declare(s) that there is no conflict of interest regarding the publication of this paper.

\section{References}

1. Oyoua 0. Ocular Trauma (Bilan 2 years of activity in the ophthalmology department of the CHU of Cocody ). Thesis Med. Abidjan 1977:116.

2. MC Kante. Epidemiological aspects of ocular morbidity in reference health center of the commune $\mathrm{V}$ of Bamako district from January to December 2009. Thesis Med Bamako, 2010.

3. Kamate SSC. Eye injuries in the work place in Koulikoro. Koulikoro Med 2006.Thèse 2003 to 2010 .

4. Sebilleau V, PL Cornut, Janin H, Denis PH, et al. Epidemiological analysis of ocular trauma to eye emergencies examined between March and April 2007: about 1,000 cases. J Fr Ophthalmol. 2008;31(1):18.

5. Khalki H. Ocular Trauma (About 408 cases). These Fes Med, 2010.
6. A Lam, Ndiaye MR. Eye injuries in Senegal, epidemiological and statistical review of 1872 case. Médecine Black Africa. 1992;39(12):810-815.

7. Gbe K, Fanny A, F Coulibaly, Boni S, et al. clinical aspects and management of wounds in children cornéo sclérales about 100 cases. J Fr Ophthalmol. 2007;30(2):222-223 .

8. SM Seck, Agboton G, Seck CM, Gueye NN, et al. Epidemiological and clinical aspects of severe ocular injuries in Dakar hospital. J Fr Ophthalmol. 2007;30(2):212 .

9. Kaya G, G Ngouoni , Ondzotto G, Botaka E, et al. Trauma to the eye and its annexes CHU Brazzaville. Medecine Black Africa. 2008;55(10):505513 .

10. Tikwasch. Penetrating wounds in the eye of workplace accidents. Ann Oculist. 1976; 209(10):643-58.

11. Trigui A, J Masmoudi, Mhiri W, Abdelmoula S, Ben Salah S, Chaabouni F, et al. Contusive retinal detachment: a retrospective review of 48 patients. J Fr Ophthalmol. 2004;27(4):353-356 .

12. Verin P, W Williamson P. Colon Ophthalmology of the countries of development. Ophtalmol. 1994;21:880.

13. Ait Allah I. oculopalpébrales wounds in children at the University Hospital Ophthalmology Clinic Le Dantec in Dakar Dakar. Thèse Med 2012; 56 .

14. Kuhn F, Morris R , CD Witherspoon, Mann L. Epidemiology of trauma blinding in the United States Eye Injury Registry. Ophthalm Epidemiol. 2006;13(3):209-216

15. S Tchabi, Sounouvou I Yehouessi L, Facounde F, Doutétien C. Eye contusion CNHU Cotonou Benin. A about 654 cases. J Fr Ophthalmol. 2010;33(7):450-454 . doi: 10.1016/j.jfo.2010.06.009.

16. Ngondi CE, Chastonay P, Dosso A. Preventing occupational eye trauma. J Fr Ophtalmol. 2010;31(1):44-49. doi: 10.1016/j.jfo.2009.10.017.

17. Gaboune L, Benfdil N, Sayouti A, Khoumiri R, et al. Les traumatismes oculaires : aspects cliniques et épidémiologiques au CHU de Marrakech. J Fr Ophtalmol. 2007;30(2):275.

18. Kofi-Mensa Savi de Tove, Abel Rodrigue Assavedo, Patricia Yekpe, Zakari Nikiema, Olivier Biaou, et Vicentia Boco. The value of ultrasound in ocular trauma in Benin. Pan Afr Med J. 2013; 15:114. doi:10.11604/ pamj.2013.15.114.2360.

19. Frau E. Traumatismes par contusion du globe oculaire.Ophtalmol 1996; $21: 700$.

20. Aberkane J, Bertal S, Mekliche A, Tiar M. Intraocular foreign body : report of 54 cases. J Fr Ophtalmol. 2007;30(2):276-277.

21. Rouberol F,Denis P,Romanet JP,Chiquet C. Comparative study of 50 early or late-onset retinal detachments after open or closed globe injury. Retina. 2011;31(6):1143-1149. doi: 10.1097/ IAE.0b013e3181f9c22e.

22. Levin LA, Beck RW, Joseph MP, Seiff S, Kraker R. The treatment of traumatic optic neuropathy: the International Optic Nerve Trauma Study. Ophthalmol. 1999;106(7):1268-1277.

23. Aaberg TM. Macular holes: a review. Surv Ophthalmol 1970; 15:13962.

24. Frau E. Trous maculaires. Réalités ophtalmologiques. 2012;190:1-5.

25. Scott RA,Ezra E,West JF,Gregor ZJ. Visual and anatomical results of surgery for long standing macular holes. $\mathrm{Br} \mathrm{J}$ Ophtalmol. 2000;84(2):150-153. 